\title{
Designing Dippler — A Next-Generation TEL System
}

\author{
Mart Laanpere, Hans Põldoja, and Peeter Normak \\ Tallinn University, Institute of Informatics, Narva mnt 25, 10120 Tallinn, Estonia \\ \{mart. laanpere, hans.poldoja, peeter.normak\} @tlu.ee
}

\begin{abstract}
This paper discusses the conceptual design of Digital Learning Ecosystems, which, as we argue, are becoming the foundation of nextgeneration Technology-Enhanced Learning systems (TEL systems). We illustrate our argument by a case study on design and development of a Dippler ecosystem. First, the framework for identifying the generations of TEL systems is described and expectations towards next generation of TEL systems are drawn from the literature review. After that, the dialectics of ongoing mainstream discourse (LMS vs PLE) is analysed and platform for reaching the synthesis is drawn. As we argue, the next-generation TEL systems are better understood if not referred as "learning environments", but rather as Digital Learning Ecosystems. Finally, process and results of a design-based research on Digital Learning Ecosystem called Dippler is described and discussed.
\end{abstract}

Keywords: learning environment, socio-technical transition, digital learning ecosystem, design-based research.

\section{Socio-Technical Transitions and Software System Generations}

In the scope of this study, we refer to various types of software application with educational purpose as Technology-Enhanced Learning systems (TEL systems). We are focusing at major shifts in technological platforms of TEL systems across the last 50 years, but also in the ways teachers and students have been using them. As we are interested not only in the structure and design of learning-related software systems, but also their implementation patterns, we decided to set a wider perspective on TEL system as a complex socio-technical system, involving various political, economical, academic and technological aspects.

There is a solid academic foundation for studying socio-technical transitions, starting from Schumpeter [1] who interpreted technological discontinuities as creative destruction, which is a natural part of multi-dimensional innovation process involving changes in products, production processes, markets, supplies and organisations. Christensen [2] has shown that evolution within a technology generation is taking the form of a S-shape curve (see Fig. 1). Ansari \& Garud [3] have used Christensen's approach to explore inter-generational transitions in the context of mobile service generations, where changes in transmission speed within a mobile service generation took a form of S-shape curve. 


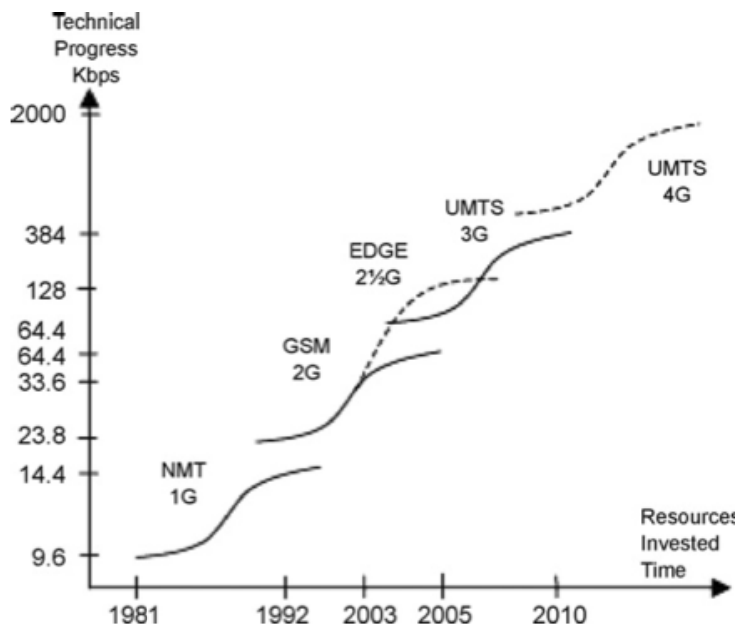

Fig. 1. S-shapes in mobile service generations [2]

Although the concept of Web 2.0 as the next generation of the WWW has been critically disputed [4], it illustrates well the fact that sometimes the reason for claims of a new generation comes mainly from the social context (incl. the radical change in technology usage patterns) and not from emergence of disruptive technology.

While it is evidently much easier to identify technology generations in case of mobile services than in case of learning-related software applications, we argue that it makes sense to conceptualise generation changes also in case of TEL systems. We believe that the era of LMS is coming to its end. Figure 2 below illustrates (yet, does not prove) our claim by showing the stagnation in the number of Moodle instances around the world. However, an increasing number of authors [5, 6, 7] argue for emergence of next generation TEL systems, which will replace traditional Learning Management Systems.

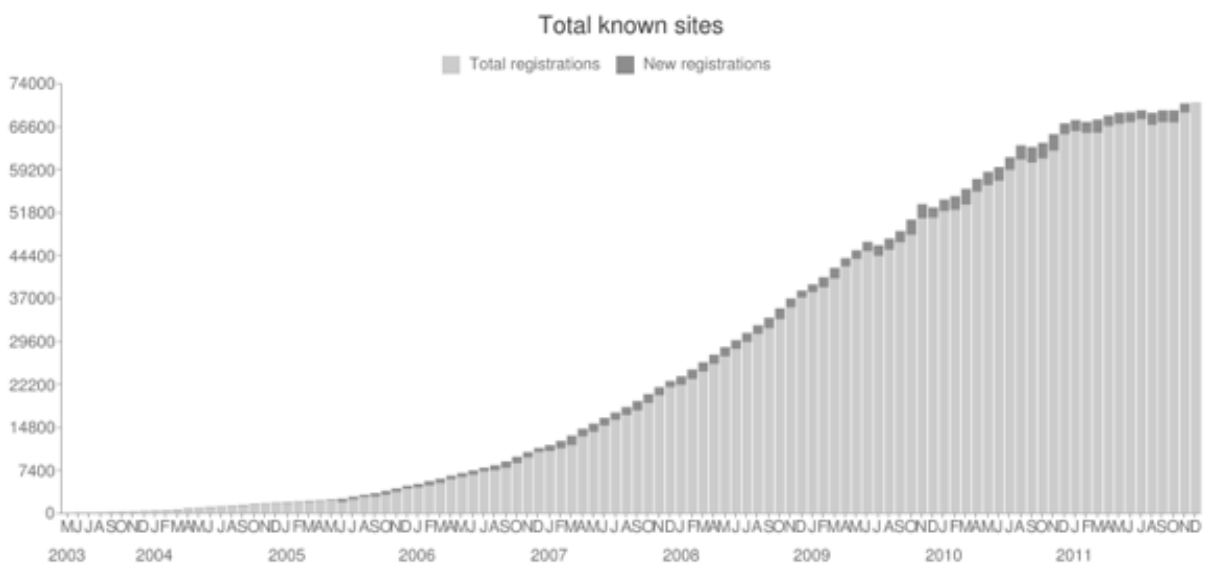

Fig. 2. S-shape curve illustrating the end of growth in Moodle installations worldwide [8] 
Our aim is to provide a justification and a new conceptual framework for nextgeneration TEL system so it could be coherent with digital ecosystems approach.

\section{Identifying the Generations of TEL Systems}

Some of the key concepts in the domain ontology of Technology-Enhanced Learning (e.g. Virtual Learning Environment, Learning System, e-learning platform, educational software) are not defined by the TEL community in a consistent and consensus-based manner. The reason for this peculiarity could be that TEL domain is not yet mature, or, due to its inter-disciplinary character, it is open to discourses and vocabularies which are taken over from other domains.

In this paper, we tried to establish a sound system of concepts, which is coherent with both existing TEL practices and theories, as well as with our proposed framework of digital learning ecosystems. Venn diagram on the Figure 3 below illustrates the proposed set of concepts for domain ontology of TEL systems.

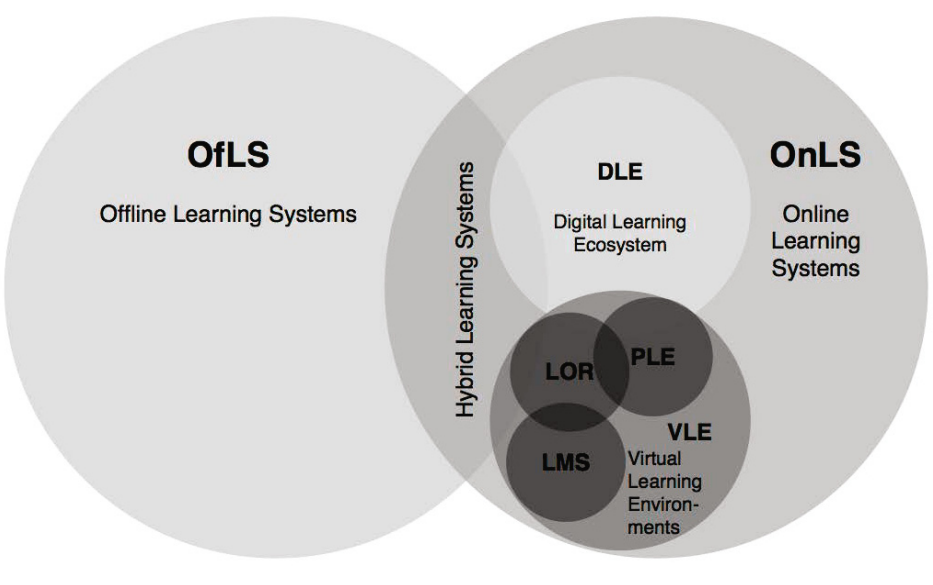

Fig. 3. Inter-relation of key concepts in the domain of TEL systems

First, TEL systems are either offline or online learning systems. Offline learning systems (e.g. desktop software used for learning and teaching, drill programs, multimedia textbooks on CD-s) can be seen as the first generation of TEL systems. The second generation of TEL systems (Virtual Learning Environments, VLE) appeared with the emergence of WWW and online learning systems. Virtual Learning Environment is defined as "a software system that combines a number of different tools that are used to systematically deliver content online and facilitate the learning experience around that content" [9]. The most prominent type of VLE are Learning Management Systems (LMS; can be also called Course Management Systems), which became the mainstream among second-generation TEL systems. LMS is defined as "a wide range of systems that organise and provide access to online learning services for students, teachers, and administrators" [10]. In parallel with LMS, Learning Object Repositories (LOR) appeared as the content was separated from the software and 
made reusable. Some LMSs also include a built-in LOR, thus a slight overlap on Fig. 3. We argue that the rise of Personal Learning Environments (PLE) was scaling up since 2008 as a form of democratic reaction and dialectic anti-thesis against closed and rigid nature of LMS. PLE is still a kind of VLE, but it is not (in most cases) especially designed for educational purposes and did not become a next-generation TEL system in itself, as it was argued by Mott [7]. A blog-based PLE causes some usability and privacy issues and together with growing tension between PLE and LMS, these two factors are creating a fruitful ground for the new generation of TEL systems: Digital Learning Ecosystems (DLE). Uden et al [11] have defined DLE as an integrated system of mutually connected/interacting digital species and their environment. However, their definition does not specify, which entities are interpreted as "biotic" (evolving, active) part of DLE and which parts are seen as "abiotic" environmental factors. To address this issue, we define DLE as an adaptive sociotechnical system consisting of mutually interacting digital species (tools, services, content used in learning process) and communities of users (learners, facilitators, experts) together with their social, economical and cultural environment. While the second generation of TEL systems interpreted software systems as an environment where learners and teachers interacted with each other as well as with learning resources, we propose to turn the roles upside down for DLE. In DLE, the symbiotic "species" or "organisms" are various interacting software tools and services along with their user and developer communities, while social, economical and cultural context plays the role of the "environment" for them. This is a change of paradigm, which will help us better understand, analyse and design the future tools and services to enhance learning. Table 1 below depicts generation changes in TEL systems in four dimensions: software architecture, pedagogical foundation, content management, dominant affordances.

Table 1. Dimensions for distinguishing inter-generational differences of TEL systems

\begin{tabular}{|c|c|c|c|}
\hline Dimension & 1st generation & 2nd generation & 3rd generation \\
\hline Software architecture & Desktop software & $\begin{array}{l}\text { Single-server } \\
\text { monolithic system }\end{array}$ & $\begin{array}{l}\text { Cloud architecture, } \\
\text { mobile clients }\end{array}$ \\
\hline $\begin{array}{l}\text { Pedagogical } \\
\text { foundation }\end{array}$ & $\begin{array}{l}\text { Stimulus-response- } \\
\text { reinforcement }\end{array}$ & Pedagogical neutrality & $\begin{array}{l}\text { Social constructivism, } \\
\text { connectivism }\end{array}$ \\
\hline Content management & Content was integrated & $\begin{array}{l}\text { Separated from } \\
\text { software, re-usable }\end{array}$ & $\begin{array}{l}\text { Open, web-based, } \\
\text { embeddable }\end{array}$ \\
\hline Dominant affordances & Presentation, drill, test & $\begin{array}{l}\text { Presentation, } \\
\text { assignments, } \\
\text { discussions }\end{array}$ & $\begin{array}{l}\text { Reflection, sharing, } \\
\text { remixing, tagging }\end{array}$ \\
\hline
\end{tabular}

Geels [12] proposes a Multi-Level Perspective (MLP) as an analytic framework for studying changes in socio-technical systems on three levels of aggregation: macro (socio-technical landscape), meso (technological regime or paradigm) and micro (niches: spaces of experimentation, protected from market pressure), see Fig.4 below. Radical innovation happens mainly on the micro level, in niches appearing outside of dominant technological paradigm, as a result of changes in macro-level landscape and influencing through dynamic interplay the meso-level technological regime. MLP suits well to analyse also the ongoing generation change in TEL systems. Current technological regime in TEL is clearly associated with the dominance of LMS, radical innovation happens in niches emerged on the Web 2.0 landscape, where increasing 


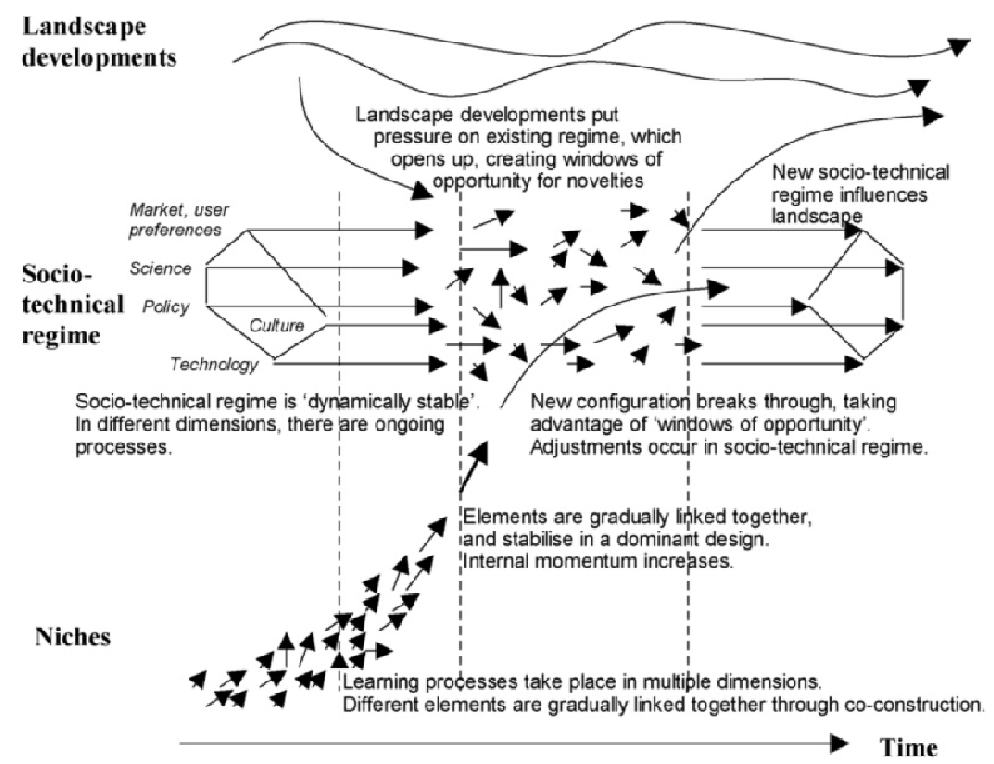

Fig. 4. A dynamic multi-level perspective on socio-technical transitions [13]

number of learners and educators find more flexible, open and social affordances to support their self-directed learning.

The number of niche-seeking experiments involving blogs and other social media tools in teaching and learning have been steadily increasing in universities, one evidence of this trend can be drawn from [14]. All together 77 academic publications from 2006 to 2011 were included in an extensive literature review on personal learning environments, involving 9 case studies from 2006, 19 from 2008 and 23 from 2010, demonstrating clearly the up-scaling of this phenomenon. While blog-based Personal Learning Environments are easy to implement on the level of single innovative teachers, these are hard to scale up to institutional level, even more difficult to integrate with existing university information systems. We argue that the next-generation TEL systems should combine the strengths of both approaches: ease of management, scalability and privacy of LMS and, on the other hand, flexibility, learner control and personalisation of PLE.

\section{Methodology: Design-Based Research}

The general research approach of this study was following the design-based research methodology [15]. This iterative way of doing research is increasingly used in learning sciences to design and implement pedagogical interventions and to test them in a real learning environment.

Leinonen et al [16] claim that the design of a product should communicate the theoretical findings made during the design process. For designing learning tools they 
propose a research-based design approach that sees final software prototype as hypothesis - potential solutions to the design challenges defined during the process. When designing Dippler as a set of software products we have followed the phases of research-based design process, which will be followed by design-based research interventions using the Dippler prototype as hypothesis.

The first phase (contextual inquiry) aimed to define the context and preliminary design challenges. The context of this study was blended learning and fully online courses in higher and vocational education. The design challenge was to combine the strengths of PLE and LMS approaches into a next generation online learning system. In the contextual inquiry phase we have conducted a number of studies on using weblogs and other social media tools in formal higher education courses [17, 18]. These studies have indicated that there is a need for a more structured online learning system that would (1) allow learners to continue using social media tools while (2) making it easier to follow and coordinate learning activities for the facilitator and (3) to manage and support the system at the institutional level. The contextual inquiry phase involved also trying out alternative approaches for managing blog-based courses. We developed two software prototypes for different course settings. LePress is a WordPress plugin that allows create courses and to manage course assignments [19]. EduFeedr is an aggregator for blog-based courses that doesn't require any plugin in a learner blog [20]. These prototypes helped us to refine the final requirements for Dippler.

The second phase of research-based design process is participatory design where important stakeholders are involved in the design process. Here we combined participatory, pedagogy-driven design with scenario-based design [21]. We prepared four scenarios that described typical use cases of Dippler: (1) facilitator sets up a course, (2) learner sets up a weblog and enrolls to the course, (3) submitting assignments and giving feedback, and (4) moving Dippler blog to another university. These scenarios were evaluated in a participatory design session involving 4 lecturers and students who had previous experience with various online learning environments.

The next phase entailed product design, aiming to define the use cases and basic interaction with the system. In that phase we wrote agile user stories [22] that were negotiated and prioritized in a web-based software project management tool Trac ${ }^{1}$. Various interaction design methods such as paper prototyping [23] and card sorting were used to design the user interface for Dippler.

We are currently in the final phase of research-based design process. We have produced a functional software product as hypothesis and completed pilot-testing it during four months in two MA-level courses. Feedback from these pilot courses will be used to evaluate the design decisions. Real data from actual use will help to refine the user interface details and to develop the next version of the Dippler.

\section{Context of and Requirements for Dippler Project}

In order to promote and develop e-learning nationwide, two consortia have been established under the lead of Estonian IT Foundation: Estonian e-University and

${ }^{1}$ http: //trac.htk.tlu.ee/iva2 
Estonian e-Vocational School. One example of joint efforts was that instead of acquiring by each university separately an institutional WebCT/BlackBoard licence, a country licence was bought for a central LMS server. Similarly, a number of centralised e-learning services (LOR, video-hub) were implemented or developed, including a next-generation TEL system called Dippler. Initially the following general requirements for Dippler were specified, as a result of a literature review and participatory design session:

- Use of Semantic Web and Web 2.0 technologies (RSS, folksonomies, web services, widgets, embedding, semantic annotation, ontologies).

- Modularity and open source code (GNU LGPL or BSD license), which would allow community based development.

- Different levels of use: suitable for both beginners and advanced users.

- Compatible with learning technology standards and specifications (LOM, QTI, SCORM, LD, Common Cartridge etc).

- Interoperability with other TEL tools (blogs, wikis, repositories).

- Support for Single Sign-on and authentication with OpenID and ID card.

- Multilingual and easily localized.

- Possibility to add individual tools and services, personalize the look and feel.

- Possibility to apply different business models.

- Powerful Learning Analytics possibilities.

- Compliance to general software requirements: scalable, secure, welldocumented, adaptable, easy installation and administration.

Based on these requirements, the iterative design process started in 2010 and software was ready to be implemented in two pilot courses in spring term 2012.

\section{Software Implementation}

Dippler is implemented as a set of distributed online tools and services, not as a monolithic server software. Technical implementation of Dippler consists of three core components:

- Back-Office Service (BOS): a Java-based middleware application together with SOAP Web services and MySQL database that is used for storing data and communicating with other components of Dippler ecosystem,

- Dippler Administrator (DiA): a PHP application with institutional interface and structures (e.g. departments, curricula, domain ontologies) for setting up, managing and evaluating courses and conducting powerful learning analytics,

- Dippler Plugin for WordPress (DiP): which turn learners' blogs into enhanced PLEs, which communicate with BOS in order to enroll to courses, receive assignments and submit homework. Student can disconnect her blog from home institution, but all artefacts created and received during the course will remain in her Personal Learning Environment. The same blog can later be re-connected with DiA of any other university or school using Dippler. 
These three core components form the heart of a larger digital learning ecosystem, where learners use their personal WordPress blogs, learning resources are stored in various Web 2.0 environments (SlideShare, YouTube, Issuu) and various social media tools can be connected with Dippler (via RSS or iFrame widgets). Dippler is also able to re-use learning objects created and/or hosted by other learning technology tools: our self-developed test authoring tool Questr, Learning Object authoring tool LeMill, and Learning Object Repository Waramu. An iPhone/iPad client for Dippler has also been developed.

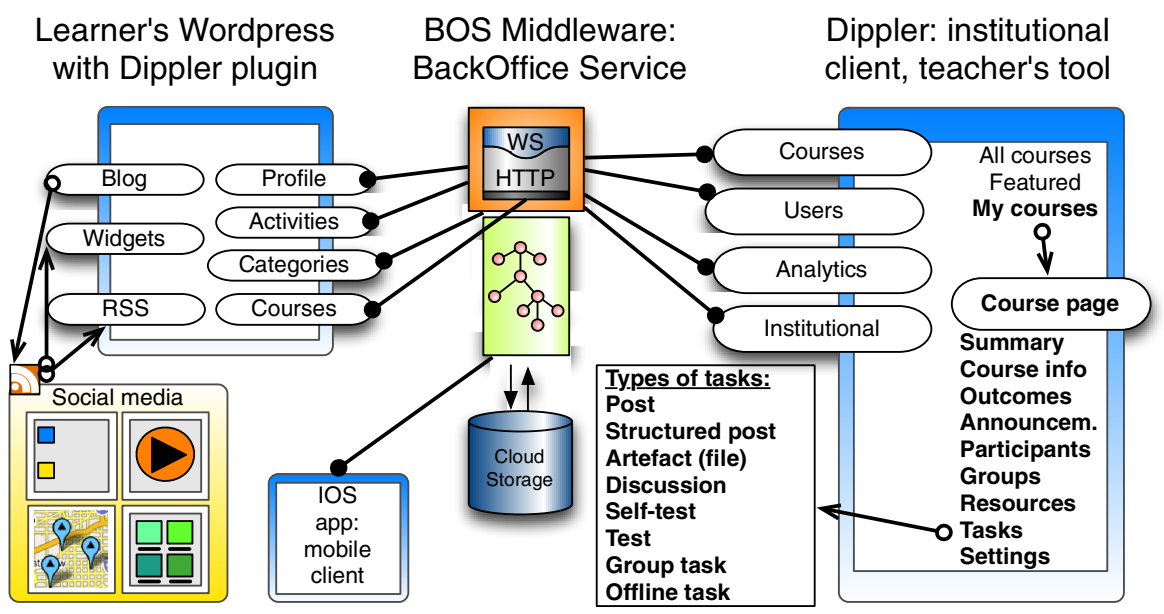

Fig. 5. Conceptual design of Dippler ecosystem

DiA acts as a catalogue of online courses and facilitators interface for managing a course. Course page is divided into 9 sections (see Fig. 5). Course feed page displays recent announcements, assignments and activity stream of the course. Learning outcomes section allows facilitator to specify learning outcomes that can be later attached to assignments, evidences in learner portfolio and other relevant objects. In the assignments section it is currently possible to create six types of tasks (free post, pre-structured post, file upload, self-test, test, group task, embedded widget), more types will be implemented in the future. In order to guide facilitators to use web-based open educational resources it is not possible to upload learning resources as files, learning resources can be only added as links or embeds. Dippler is able to retrieve learning resource metadata from YouTube or Slideshare based on URL of a resource and display the embedded resource. Both assignments and learning resources can be annotated with domain ontology concepts, which connect them to specific learning outcomes and are allowing more meaningful learning analytics.

Learners will use their WordPress blogs as personal learning portfolios. In order to connect their blog to BOS service they need to activate Dippler plugin (DiP) for WordPress. The plugin extends the blog's user interface with some new pages and widgets: course feed, assignments, learning resources, etc. Learners submit their 
responses to assignments as blog posts that will be copied to BOS and connected with a selected learning outcome as well as some concepts from domain ontology. Dippler plugin allows the facilitator to keep her feedback and grades private. Otherwise learners have full control over their blogs: they can change its outlook, add sidebar widgets, plugins, pages, blogroll etc.

Dippler is open-source software, distributed under Apache 2.0 license. The source code of Dippler can be downloaded from http://trac.htk.tlu.ee/iva2.

\section{Conclusion and Future Research}

This paper proposed a conceptual framework for next-generation TEL systems - Digital Learning Ecosystems, along with an illustrative case study on designing and developing the Dippler platform. The case study followed the participatory design-based research methodology, resulting with an innovative ecosystem of open-source tools and open learning resources, which is designed to combine the strengths of blog-based Personal Learning Environments with that of traditional Learning Management Systems.

In the next phase of our design-based research, we are planning to expand and cultivate the digital learning ecosystem of Dippler by integrating or associating it with new learning tools (e.g. concept mapping tool CMapTools, Knowledge Building tool FLE4, Twitter, Wookie widget server) and training or inviting the new groups of users, communities, educational institutions to populate the system with activities. As all activities in Dippler ecosystem leave semantically rich traces to BOS database, we foresee it as a new powerful tool for new type of learning analytics in Digital Learning Ecosystems.

Acknowledgments. This research was funded by Estonian Ministry of Education and Research, targeted research grant No. 0130159s08. Development of Dippler was funded by Estonian IT Foundation and BeST program of European Social Fund.

\section{References}

1. Schumpeter, J.A.: Business Cycles: A Theoretical, Historical and Statistical Analysis of the Capitalist Process. McGraw-Hill, New York (1939)

2. Christensen, C.M.: The Innovator's Dilemma: When New Technologies Cause Great Firms to Fail. Harvard Business Review Press, Cambridge (1997)

3. Ansari, S., Garud, R.: Inter-generational transitions in socio-technical systems: The case of mobile communications. Research Policy 38(2), 382-392 (2009)

4. Scholz, T.: Market Ideology and the Myths of Web 2.0. First Monday 13(3) (2008)

5. Rajagopal, K., Joosten-ten Brinke, D., Van Bruggen, J., Sloep, P.: Understanding personal learning networks: Their structure, content and the networking skills needed to optimally use them. First Monday 17(1) (2012)

6. Casquero, O., Portillo, J., Ovelar, R., Benito, M., Romo, J.: iPLE Network: an integrated eLearning 2.0 architecture from a university's perspective. Interactive Learning Environments 18(3), 293-308 (2010) 
7. Mott, J.: Envisioning the Post-LMS Era. EDUCAUSE Quarterly 33(1) (2010)

8. Moodle Statistics, http://moodle.org/stats

9. Weller, M.: Virtual Learning Environments: Using, Choosing and Developing your VLE. Routledge, Oxon (2007)

10. Paulsen, M.F.: Online Education Systems: Discussion and Definition of Terms (2002), http: //nettskolen.nki.no/forskning/Definition\%20of\%20Terms.pdf

11. Uden, L., Wangsa, I.T., Damiani, E.: The future of E-learning: E-learning ecosystem. In: IEEE Conf. on Digital Ecosystems and Technologies, pp. 113-117. IEEE, Cairns (2007)

12. Geels, F.W.: Technological transitions as evolutionary reconfiguration processes: a multilevel perspective and a case-study. Research Policy 31(8-9), 1257-1274 (2002)

13. Genus, A., Coles, A.-M.: Rethinking the multi-level perspective of technological transitions. Research Policy 37(9), 1436-1445 (2008)

14. Buchem, I., Attwell, G., Torres, R.: Understanding Personal Learning Environments: Literature review and synthesis through the Activity Theory lens. In: Proceedings of the The PLE Conference 2011, Southampton, UK, July 10-12 (2011)

15. The Design-Based Research Collective: Design-Based Research: An Emerging Paradigm for Educational Inquiry. Educational Researcher 32(1), 5-8 (2003)

16. Leinonen, T., Toikkanen, T., Silvfast, K.: Software as Hypothesis: Research-Based Design Methodology. In: Proceedings of the Tenth Anniversary Conference on Participatory Design 2008, pp. 61-70. Indiana University, Indianapolis (2008)

17. Väljataga, T., Pata, K., Tammets, K.: Considering Students' Perspectives on Personal and Distributed Learning Environments in Course Design. In: Lee, M.J.W., McLoughlin, C. (eds.) Web 2.0-Based E-Learning, pp. 85-107. IGI Global, Hershey (2011)

18. Väljataga, T., Põldoja, H., Laanpere, M.: Open Online Courses: Responding to Design Challenges. In: Proceedings of NBE 2011, pp. 68-75. University of Lapland, Rovaniemi (2011)

19. Tomberg, V., Laanpere, M., Lamas, D.: Learning Flow Management and Semantic Data Exchange between Blog-Based Personal Learning Environments. In: Leitner, G., Hitz, M., Holzinger, A. (eds.) USAB 2010. LNCS, vol. 6389, pp. 340-352. Springer, Heidelberg (2010)

20. Põldoja, H.: EduFeedr: following and supporting learners in open blog-based courses. In: Open ED 2010 Proceedings, UOC, OU, BYU, Barcelona (2010)

21. Carroll, J.M.: Making Use: Scenario-Based Design of Human-Computer Interactions. The MIT Press, Cambridge (2000)

22. Cohn, M.: User Stories Applied: For Agile Software Development. Addison-Wesley, Boston (2004)

23. Snyder, C.: Paper Prototyping: The Fast and Easy Way to Design and Refine User Interfaces. Morgan Kaufmann, San Francisco (2003) 